\title{
Feeding corn and barley based concentrates to grazing dairy cows. II. Plasma glucose and insulin concentrations after glucose challenge
}

\author{
GA Gagliostro 1, SE Lavandera 2 \\ IINTA EEA Balcarce, CC 276-7620 Balcarce ; ${ }^{2}$ Consejo Nacional de Investigaciones \\ Cientificas y Técnicas (CONICET), Argentine
}

Protein and energy availabilities in the rumen may be umpaired in cows fed autumn-winter forages and a risk of ammonia toxicity may develop. Hyperglycaemia and reduced insulin release were reported in hyperammonemic diets (Fernández et al, 1988, J Anim Sci, 66, 32593266 ; Visek, 1984, J Dairy Sci ,67, 481-498).

Animals and treatments have been described by Gagliostro et al (1995, this issue). In week 4 , jugular blood samples were taken before (G$0)$, and 5 (G-5), $10(\mathrm{G}-10)$ and $15(\mathrm{G}-15)$ minutes after an intravenous glucose challenge (100 $\mathrm{mg} / \mathrm{kg}$ body weight). Fractional rate of glucose clearance $(k)$ was calculated as the slope of the regression of time on $\ln C$ where $\mathrm{C}=$ glucose concentration at times 5,10 and 15 minus G-0 glucose concentration. In week 1 , jugular $(\mathrm{J})$ and mammary $(\mathrm{M})$ blood samples were taken to evaluate apparent mammary uptake of metabolites. Plasma was analysed for urea, glucose, triglycerides (TG) and free fatty acids (FFA) using enzymatics kits. Plasma insulin was determined by radioimmunoassay. Data were analysed using a split-plot design with treatment as main plot and sampling time as secondary plot.

Basal (G-0) glucose concentrations were 69.3, 69.2 and $72.3 \mathrm{mg} / \mathrm{dl}$ for $\mathrm{PA}, \mathrm{CO}$ and $\mathrm{BA}$. Glucose concentration in $\mathrm{G}-5, \mathrm{G}-10$ and $\mathrm{G}-15$ samples were higher than $G-0(P<0.05)$ but similar between treatments. Averaged values from all treatments showed increases in glucose concentration of $48.8,38.7$ and 31.4 $\mathrm{mg} / \mathrm{dl}$ in $\mathrm{G}-5, \mathrm{G}-10$ and $\mathrm{G}-15$ respect to $\mathrm{G}-0$ $(P<0.05)$. Glucose concentration inmediately after the injection (131.9, 130.7 and 141.9 $\mathrm{mg} / \mathrm{dl})$, distribution volume $(40.22,41.56$ and $40.33 \mathrm{I})$ and $k$ values $(-0.041,-0.045$ and -0.059) were similar in PA, CO and BA. Decreases in FFA after glucose challenge did not differ between treatments $(P<0.60)$. Averaged values from all treatments showed lower $(\mathrm{P}<0.05)$ values in $\mathrm{G}-5(334 \mu \mathrm{Eq} / \mathrm{l}), \mathrm{G}-10$ $(327 \mu \mathrm{Eq} / \mathrm{l})$ and $\mathrm{G}-15(289 \mu \mathrm{Eq} / \mathrm{l})$ respect to $\mathrm{G}-0$ $(418 \mu \mathrm{Eq} / \mathrm{l})$. Plasma urea was higher $(P<0.05)$ at G-10 (17.84 $\mathrm{mg} / \mathrm{dl})$ and $\mathrm{G}-15(17.73 \mathrm{mg} / \mathrm{dl})$ respect to $\mathrm{G}-0(16.06 \mathrm{mg} / \mathrm{dl})$. Basal $(\mathrm{G}-0)$ plasma insulin was higher in BA respect to $\mathrm{CO}$. Insulin release after glucose injection was similar between treatments $(P<0.11)$. Surface under the insulin curve tended to be lower $(\mathrm{P}<0.09)$ in $\mathrm{CO}(304 \mu \mathrm{U} / \mathrm{min})$ respect to $\mathrm{PA}$ $(417 \mu \mathrm{U} / \mathrm{min})$ and $B A(469 \mu \mathrm{U} / \mathrm{min})$. Insulin $\mathrm{k}$ values tended to be lower in PA $(-0.02794)$ respect to $C O(-0.04566)$ and $B A(-0.05848)$. $J-M$ differences were similar between treatments $(P>0.10)$. Significative apparent mammary uptake were observed for glucose, TG and FFA but not for urea.

Glucose metabolism and insulin release after glucose challenge did not differ between unsupplemented cows exposed to higher ammonia absorption and cows receiving concentrates with different rumen starch degradability.

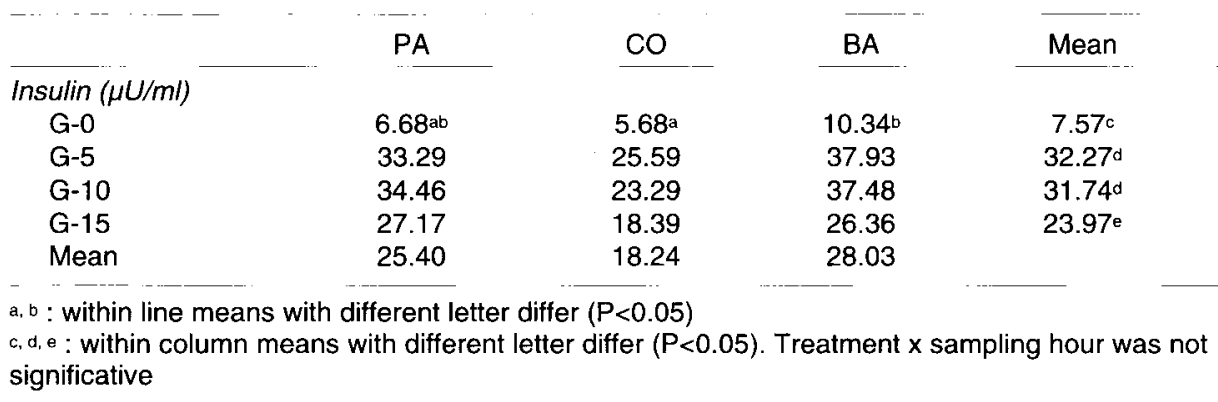

